\title{
Different Methods of Treatment of Trochanteric Fractures in Elderly
}

Ayman M. Abbas, Galal El Din H. Kazem, Abd El Salam Abd El Alem, Saad A. Shoulah

\begin{abstract}
Department of Orthopaedics, Benha faculty of medicine, Banha University, Egypt.

Correspondence to: Ayman M. Abbas, Department of Orthopaedics, Benha faculty of medicine, Banha University, Egypt.
\end{abstract}

Email:

ayman.yougi@gmail.com

Received: 9 September 2019

Accepted: 17 October 2019

\section{Abstract:}

Background: Trochanteric femoral fractures constitute $3 \%$ of all fractures and a large portion of fractures after the age of 60 . Trochanteric femoral fractures in elderly usually occur due to a low-energy trauma and can be treated successfully with internal fixation or prosthesis depending on the patient's age and general condition and also the quality of the bone. Aim and Objective: This is a systematic review to evaluate different techniques of fixation used in management of intertrochanteric fracture, regarding the efficacy results and complication of each technique in the literature. Methods: A review was performed using the Cochrane Central Register of Controlled Trials, PubMed, and MEDLINE as database for search. Results: the results of the study revealed that the percent of changes were $44.69 \%$ of RT side group A, $45.26 \%$ of RT side group B, $40.86 \%$ of LT side group A, and $45.90 \%$ of LT side group B with no significant difference between the studied groups. included studies focusing on intertrochanteric fracture fixation in elderly patients as the main

research point, if it was not the main point, paper was excluded. Conclusion: Prosthetic replacements can treat unstable intertrochanteric fracture well, if operative indication is correctly selected. It is suitable for elderly patients and the operation should be performed by experienced surgeons.

Keywords: Trochanteric, Femoral, Fractures, MEDLINE. 



\section{Introduction}

Trochanteric femoral fractures constitute 3\% of all fractures and a large portion of fractures after the age of 60. Trochanteric femoral fractures in elderly usually occur due to a low-energy trauma and can be treated successfully with internal fixation or prosthesis depending on the patient's age, general condition and also the quality of the bone. ${ }^{(1)}$

If they are not adequately treated, they may cause a considerable change in the quality of life. The trauma becomes more severe leading to prolonged bed ridden, and leads to worsening of existing disease, which is the major cause of mortality from this fracture especially in elderly ${ }^{(1)}$.

Trochanteric fracture femur occurs in the area between the greater and lesser trochanter and may involve these two structures. Trochanteric fractures make up to $45 \%$ of all hip fractures. This region consists of weight bearing trabeculae and has a good amount of cancellous bone and vascularity thus minimizing the risk of avascular necrosis and non-union. Biomechanically, the structural composition of the femur (thigh bone), is adapted in response to the mechanical environment that it is subjected to. Trochanteric fractures can be classified in many ways viz, Evan's classification,
Kyle's Classification, Jenson's classification. All of them divided this fracture into stable fractures and unstable fractures (reverse oblique and coronal split fractures).

Evans Classification $^{(3)}$ :

In 1949, Evans published his classification on intertrochanteric (IT) fractures

\section{Jensen's Modification of the Evans} Classification $^{(4)}$ :

Jensen (1975) later modified Evans classification into three groups displaced or undisplaced stable 2-fragment fractures, unstable 3-fragment fractures with greater or lesser trochanter fracture and 4-fragment fractures

\section{Kyle's Classification $^{(6)}$ :}

Kyle has classified trochanteric fractures into four types.

Various treatment modalities ${ }^{(6)}$ have been introduced for the reduction and fixation of trochanteric fractures, ranging from conservative treatment to operative intervention in form of different techniques of internal and external fixation including dynamic hip screw (DHS), proximal femoral nail, trochanteric fixation nail (TFN), gamma nail, dynamic compression screw , proximal femoral plate, external fixator, bipolar hemi-arthroplasty . All of which have their specific advantages and disadvantages 
The application of the contemporary operational methods substantially reduces the mortality risks, in comparison to the conservative methods of treatment, furthermore, the contemporary methods can result in fewer percentages of complications, and valid functional results ${ }^{(6)}$.

The goal of operative treatment is strong and stable fixation of the fracture fragment. Dynamic hip screw (DHS) or Sliding Screw Fixation ${ }^{(7)}$ is a type of orthopedic implant designed for fixation of certain types of hip fractures. The Gamma Nail ${ }^{(8)}$ is the latest advance in the treatment of trochanteric fractures based on intramedullary nailing principles during closed procedures. Its design is based on Küntscher's Y-nail and locking intramedullary (IM) nails.

Proximal femoral nail ${ }^{(9)}$ Helical blade PFN has been introduced as an intramedullary option in recent years. Helical PFN is more suitable implant for unstable trochanteric fractures in elderly, osteoporotic patients' population.

Conservative treatment ${ }^{(10)}$ in which, applying traction to the injured limb either via a pin inserted into the tibia (skeletal traction), or using adhesive tape or bandages applied to the injured leg (skin traction). Between four to nine kilo-grams of weight is then applied to reduce the fracture. Traction is then maintained whilst the fracture heals, a period of two to four months.

\section{Materials and Methods}

A systematic review study was performed using the Cochrane Central Register of Controlled Trials, PubMed, and MEDLINE as database for search till the year of 2018 .

Search keywords were isolated or combined and included: intertrochanteric fracture, fixation and surgical management combined with elderly, elder or old age patients. We only included studies focusing on intertrochanteric fracture fixation in elderly patients as the main research point, if it was not the main point, paper was excluded.

This study was conducted according to the following eligibility criteria:

\section{Inclusion criteria:}

- Clinical studies with at least 2 years of follow up.

- English literatures only.

Exclusion criteria:

- Non-human studies.

- Reviews, commentaries, and general discussion papers not presenting data on impacts.

- Clinical studies with $<2$ years of follow up.

- Case report 
All abstracts were screened in duplicate. Abstracts proceeded to full-text review if they reported original data; assessed the fixation methods; included elderly participants with intertrochanteric fractures. Abstracts were excluded if they failed to meet the criteria above or if they included animals, reported nonoriginal data or included pediatric or young populations.
Abstracts selected for inclusion by either reviewer proceeded to full-text review.

For all studies, patient selection, study inclusion and exclusion criteria, patient characteristics, procedure protocol and outcomes measured were extracted using standardized data extraction forms. Outcomes for intervention, were extracted from each study.

\section{Results:}

Table 1: Studies used DHS for treatment of intertrochanteric fractures in elderly

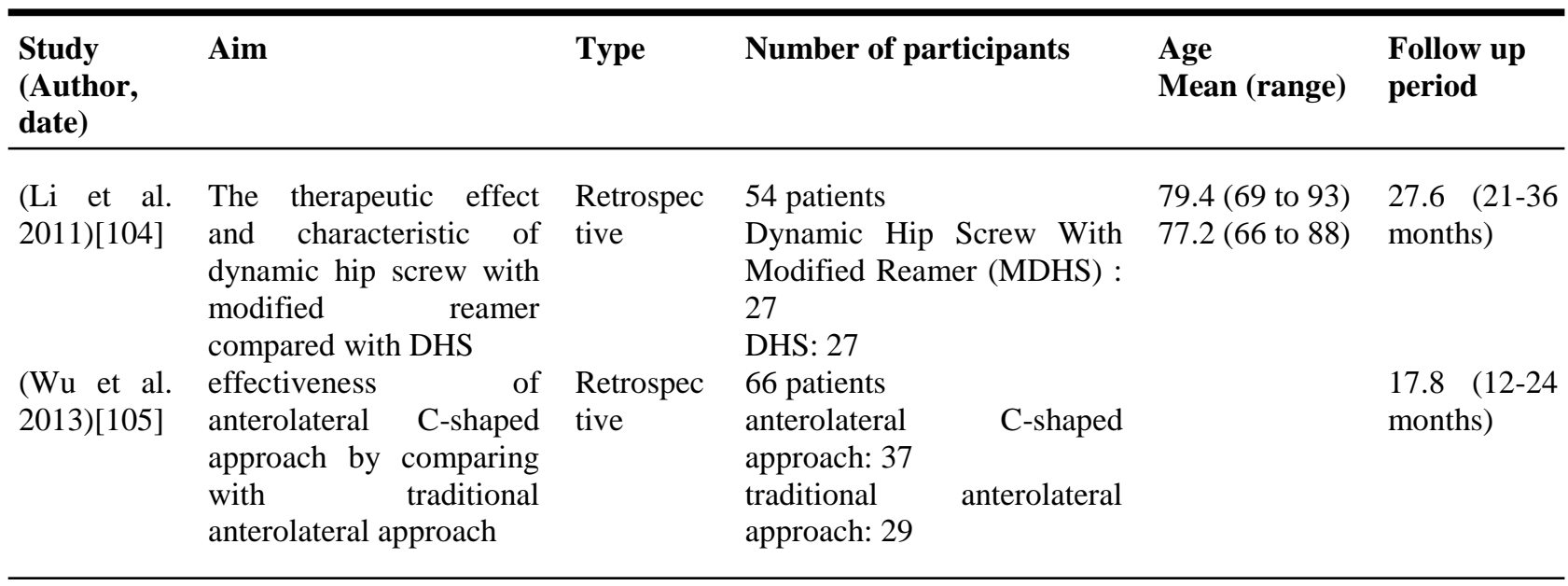

Table 2: Results of DHS for treatment of intertrochanteric fractures in elderly

\begin{tabular}{|c|c|c|c|c|}
\hline $\begin{array}{l}\text { Study } \\
\text { (Author, } \\
\text { date) }\end{array}$ & $\begin{array}{l}\text { The time of fracture } \\
\text { healing }\end{array}$ & $\begin{array}{l}\text { The forepart } \\
\text { movement time }\end{array}$ & $\begin{array}{l}\text { The } \\
\text { screw }\end{array}$ & $\begin{array}{l}\text { The Harris score of hip joint } \\
\text { function }\end{array}$ \\
\hline $\begin{array}{l}\text { (Li et al. } \\
2011)[104]\end{array}$ & $\begin{array}{l}\text { No significant difference } \\
(\mathrm{P}>0.05) \text {. } \\
\text { was higher than that of } \\
\text { MDHS }\end{array}$ & $\begin{array}{l}\text { MDHS }(14.2 \pm \\
2.1) \\
\text { DHS }(18.9 \pm 3.1) \\
(\mathrm{P}<0.05)\end{array}$ & $\begin{array}{l}\text { MDHS group }(1 \\
\text { case }) \\
\text { DHS group (8 cases) } \\
(\mathrm{P}<0.05) .\end{array}$ & $\begin{array}{l}\text { MDHS }(87.8 \pm 4.7) \\
\operatorname{DHS}(83.3 \pm 7.5)(P<0.05) .\end{array}$ \\
\hline $\begin{array}{l}(\mathrm{Wu} \text { et al. } \\
2013)[105]\end{array}$ & $\begin{array}{l}\text { 3-6 months (mean, } 4.8 \\
\text { months) }\end{array}$ & & $\begin{array}{l}\text { No loosening or } \\
\text { breaking of internal } \\
\text { fixation was } \\
\text { observed during } \\
\text { follow-up period. }\end{array}$ & $\begin{array}{l}\text { According to self-established } \\
\text { criterion, improved group was } \\
\text { significantly better than } \\
\text { conventional group in recovery } \\
\text { of hip joint motion and function } \\
\text { at } 6 \text { and } 12 \text { months after } \\
\text { operation }(\mathrm{P}<0.05) \text {. }\end{array}$ \\
\hline
\end{tabular}


Table 3: Studies on proximal femoral nail for treatment of intertrochanteric fractures in elderly

\begin{tabular}{|c|c|c|c|c|c|}
\hline $\begin{array}{l}\text { Study } \\
\text { (Author, } \\
\text { date) }\end{array}$ & Aim & Type & $\begin{array}{l}\text { Number } \\
\text { participants }\end{array}$ & $\begin{array}{l}\text { Age } \\
\text { Mean (range) }\end{array}$ & $\begin{array}{l}\text { Follow up } \\
\text { period }\end{array}$ \\
\hline $\begin{array}{l}\text { (Wan et al. } \\
\text { 2018)[106] }\end{array}$ & $\begin{array}{l}\text { To investigate the difference } \\
\text { in the effectiveness between } \\
\text { proximal femoral nail anti- } \\
\text { rotation (PFNA) and } \\
\text { proximal femoral locking } \\
\text { compression plate (PFLCP) }\end{array}$ & Retro & $\begin{array}{l}67 \text { cases } \\
\text { PFNA: } 32 \\
\text { PFLCP: } 35 \text { cases }\end{array}$ & & $\begin{array}{l}14 \quad(12-24 \\
\text { months })\end{array}$ \\
\hline $\begin{array}{l}\text { (Zhu et al. } \\
2016)[107]\end{array}$ & $\begin{array}{l}\text { To compare clinical effect of } \\
\text { closed reduction and limited } \\
\text { open reduction and internal } \\
\text { fixation with InterTan } \\
\text { intramedullary nail }\end{array}$ & Retro & $\begin{array}{l}23 \text { elderly } \\
\text {-(closed reduction } \\
\text { group): } 12 \text { cases } \\
\text {-(limited reduction } \\
\text { group): } 11 \text { cases }\end{array}$ & $\begin{array}{l}(63.6 \pm 12.1) \\
\text { years } \\
60.8 \pm 12.5) \\
\text { years. }\end{array}$ & $\begin{array}{l}13.6 \text { (12 to } \\
23 \text { months) }\end{array}$ \\
\hline
\end{tabular}

Table 4: Studies on arthroplasty for treatment of intertrochanteric fractures in elderly

\begin{tabular}{|c|c|c|c|c|c|}
\hline Study & Aim & Type & Number of participant & $\begin{array}{c}\text { Age } \\
\text { Mean (range) }\end{array}$ & $\begin{array}{l}\text { Follow up } \\
\text { period }\end{array}$ \\
\hline $\begin{array}{l}\text { (Liu et al. } \\
2008)[109]\end{array}$ & $\begin{array}{l}\text { To assess the curative } \\
\text { effect and investigate the } \\
\text { indications of total hip } \\
\text { arthroplasty } \\
\text { comminuted for } \\
\text { intertrochanteric fracture }\end{array}$ & $\begin{array}{l}\text { Interventional } \\
\text { prospective }\end{array}$ & 9 cases & $\begin{array}{l}68(48-75 \\
\text { years }) .\end{array}$ & $\begin{array}{l}11 \text { months } \\
(3 \text { months-2 } \\
\text { years })\end{array}$ \\
\hline $\begin{array}{l}\text { (Zhang et al. } \\
\text { 2013)[110] }\end{array}$ & $\begin{array}{l}\text { Clinical efficacy of } \\
\text { renovation stem revision } \\
\text { femoral head arthroplasty } \\
\text { for the treatment of } \\
\text { unstable intertrochanteric } \\
\text { fracture in the elderly. }\end{array}$ & $\begin{array}{l}\text { Prospective } \\
\text { study }\end{array}$ & 32 patients & $\begin{array}{l}83.8(80 \text { to } \\
98) \text { years old }\end{array}$ & \\
\hline $\begin{array}{l}\text { (Zhang et al. } \\
\text { 2005)[111] }\end{array}$ & $\begin{array}{l}\text { To evaluate the clinical } \\
\text { effect of bipolar long-stem } \\
\text { prosthetic replacement on } \\
\text { the treatment of } \\
\text { comminuted } \\
\text { intertrochanteric fracture } \\
\text { of hip in the elderly } \\
\text { osteoporotic patients. }\end{array}$ & prospective & $\begin{array}{l}18 \text { patients Treated with } \\
\text { bipolar long-stem } \\
\text { prosthetic replacement. }\end{array}$ & $\begin{array}{l}\text { Range from } \\
72 \text { to } 91) .\end{array}$ & $\begin{array}{l}16.2 \text { (6 to } \\
28 \text { months })\end{array}$ \\
\hline $\begin{array}{l}\text { (Cui et al. } \\
\text { 2016)[112] }\end{array}$ & $\begin{array}{l}\text { To observe the clinical } \\
\text { effect of steel cable or } \\
\text { greater trochanter } \\
\text { reattachment (GTR) } \\
\text { device combined with } \\
\text { cemented hip } \\
\text { hemiarthroplasty for } \\
\text { unstable intertrochanteric } \\
\text { fracture in elderlies }\end{array}$ & Retrospective & $\begin{array}{l}57 \text { patients received } \\
\text { cemented } \quad \text { bipolar } \\
\text { femoral head } \\
\text { replacement, using steel } \\
\text { cable or GTR device }\end{array}$ & $\begin{array}{l}83(80 \text { to } 95 \\
\text { years })\end{array}$ & 36 months \\
\hline
\end{tabular}




\begin{abstract}
(Dong and To investigate the Liao operative procedure and 2009)[113] the therapeutic effects of unstable femoral intertrochanteric fracture in elderly patients with rebuild septum bronchiale in artificial femoral head replacement.
\end{abstract}

(Wang et al. To discuss the 2018)[114] hemiarthroplasty

(Wada et al, To evaluate the clinical 2017) [115] results of rigid fixation of the greater trochanter fragment through a consecutive hemiarthroplasty series using a cementless and modular calcarreplacement prosthesis with an integrated plate (MOD-Centaur stem)
Retrospective

Retrospective

Prospective interventional
113 elderly patients (test Test group: 12-36 group):Treated with 75 years months. artificial femoral head Control replacement with group: 72.5 fixation of femoral years greater trochanter and smaller trochanter in the help of bone cement in 58 cases (control group): with gamma-type bone nail in 55 cases

66 elderly patients 85 (80 to 95 ) 2 years Hip hemiarthroplasty: 34 years old average cases

Internal fixation: 32 cases.

44 very elderly patients

89.6 years 1-year average follow-up

Table 5: Results ofcomparative studies

\section{Healing time}

\section{joint activity}

(Gashi et al. 2018) [119]

(Sun et al. In the clinical 2016) $[120]$ healing time of fracture, the PFNA group significantly differently less than that of the reconstructing calcar group $(\mathrm{P}<0.05)$.

\section{Complications}

Early mobilization was Mortality rate did not differ significantly better in hemiarthroplasty $\quad(\mathrm{p}<0.001)$ where $93.3 \%$ of patients started partial weight bearing on postoperative between the two groups, but general and mechanical complications were more common in the DHS group.

Day 1, while in the DHS group, $73.7 \%$ of patients started partial weight bearing after two weeks postoperatively.

There were significant in the incision length, operation time, blood loss volume, clinical healing time of fracture.

1 case of screw blade cutting and 1 case of deep venous thrombosis in PFNA group; there was 1 case of deep venous thrombosis in the reconstructing calcar group $\left(\mathrm{X}^{2}=0.000, \mathrm{P}=1.000\right)$.
The Harris score of hip joint function

The mean Harris Hip score was better in the hemiarthroplasty group $\quad(91.14 \quad$ vs 74.11).

There were no significant in postoperative partial weight bearing standing time, postoperative complications, hip functional score of Harris between two group. 


\section{Discussion}

Open reduction and internal fixation (ORIF) are indicated for all intertrochanteric fractures, unless the patient's medical condition unsuitable for any anesthesia, whether general or spinal.

Total hip arthroplasty has a limited role in treatment and is usually reserved for patients with coexisting severe symptomatic arthritis of the hip. External fixation is also rarely indicated but is useful as a quick procedure in patients who may not tolerate general or spinal anesthesia and can only tolerate local techniques. Medial displacement osteotomy and valgus reduction are no longer practiced, because of the severe deformities they produced and because of substantial advances in the understanding of fracture fixation.

Surgery is contraindicated if the patient has an uncontrollable or uncorrectable bleeding disorder or another non-correctable metabolic disorder with an unacceptable mortality. It is also contraindicated if the patient has a stable, non-displaced intertrochanteric fracture, can physically and mentally tolerate nonsurgical care, and declines surgery for personal reasons.

The future of intertrochanteric fracture repair focuses, in part, on preventing such fractures by means of antiosteoporosis treatments, including medications and health programs. Another focus includes fixation devices that require smaller incisions and are more forgiving, with retention of the fixation, regardless of whether the fracture is ideally reduced or has an element of instability.

A final goal is to eliminate or substantially decrease the mortality and morbidity of postoperative deep vein thrombosis (DVT) and pulmonary embolism (PE) by developing a better understanding of the clotting mechanism and the genetic, metabolic, serologic, and hormonal factors that affect the likelihood of developing PE.

Open reduction and internal fixation and Arthroplasty confined themselves to the management of unstable trochanteric fractures in people older than 70 years. Indeed, it is likely that stable fractures can be treated by internal fixation with a lower incidence of fixation complications than for unstable fractures. In parallel with treatment of people with intra-capsular fracture, arthroplasty is less likely to be considered for younger patients. Though ORIF and ARTHROPLASTY made the same basic comparison, there were important 
differences in the interventions (cemented versus cementless arthroplasty; extra medullary versus intramedullary fixation) under comparison. Individually and overall the numbers of participants of the studies were too small to be able to detect any clear differences in mortality, morbidity or function. The statistically significant difference in mortality at "three years" has to be viewed with caution for several reasons: because of (a) the underlying variable follow up ranging from 24 months to 58 months, (b) the lack of a clear difference in mortality at one year, and (c) that the causes of death between one and three years were not known. There were inadequate results for longer-term outcome including a lack of information on longerterm complications in both trials.

In summary, the evidence from these trials was insufficient to be able to draw any definite conclusions about the relative merits of each type of operation. Furthermore, ORIF and ARTHROPLASTY, in particular, had methodological flaws that could have affected their findings and gave an adequate account of long-term outcome $[11,12]$.

This review was performed in an attempt to find evidence-based support for consensus of best treatment of unstable trochanteric femoral fractures and to discuss the current state of the art of treatment. There are some limitations to this review literature since 1990 revealed a limited number of publications assessing too many different treatment methods to perform a systematic review. Moreover, methodology was found to be too defective for analysis, as for instance, method of randomization was not known in nearly half of the studies, and most did not include enough patients (power analysis was rarely presented). Many trials included both stable and unstable fractures; published studies could be used for specific analysis of results in unstable fractures. Randomized trials were selected starting from publication year 1990, as earlier study results may have been biased in favors of the sliding hip screw, because of limited experience with intramedullary devices. When we considered the results of the ORIF trials in general, treatment of unstable trochanteric fractures with extra-medullary devices showed high cut out and varus displacement rates, and a very high incidence of wound problems and infections. Treatment of unstable trochanteric fractures with intramedullary devices showed less complications and re-operations. The intramedullary fixation showed a lower risk of implant related complications, earlier and better mobilization capacity, less impaction of the fracture area and less limb shortening. Finally, other studies focused on patients 
with unstable fractures only, and found significant fracture related complications and implant failures after extra medullary treatment, whereas hardly any of these problems were seen after intramedullary stabilization. Unfortunately, none of the reviewed trials comparing intramedullary and extra medullary treatment, analyzed groups with high numbers of unstable trochanteric fractures. Based on the abovementioned limitations, attempts to find an evidence-based clinical consensus for the treatment of unstable trochanteric fractures remain unsuccessful.

As the experience of surgeons with the various intramedullary fixation systems increases, treatment results tend to improve, with less intraoperative and postoperative complications.

Modifications like adapted distal interlocking options have reduced the risk of postoperative adverse events, and emphasis on the correct positioning of the fixation device in the femoral head after optimal reduction of the fracture will help further decrease the risk of cut-out [13].

External fixation was introduced for the management of trochanteric fractures at about the same time as the first sliding internal fixation devices but its use has decreased considerably in recent years.
Studies comparing external fixation to sliding hip screws have reported superior outcomes in favor of external fixation. Collapse of the fracture into varus commonly found in unstable fractures but this seems to be well tolerated by elderly, possibly because of their low demands in activities of daily living [14-15].

\section{Conclusion}

Prosthetic replacements can well treat unstable intertrochanteric fracture if operative indication is correctly selected. It is suitable for elderly patients and the operation should be performed by experienced surgeons

\section{References}

1. Seyfettinoğlu F, Ersan O, Kovalak E, Duygun F, Ozsar B, Ateş Y. Fixation of femoral neck fractures with three screws: results and complications. Acta Orthop Traumatol Turc. 2011; 45(1):6-13.

2. Morgan JD, Somerville EW: Normal and abnormal grow that the upper end of the femur. $\mathrm{J}$ Bone Joint Surg 1960;42B: 264-272.

3. Evans, E. M. The treatment of trochanteric fractures of the femur. J. Bone Jt Surg. 1949;31B: 190-203.

4. Jensen, J. S. Classification of trochanteric fractures. Actaorthop Scand. 1980; 51:803-810.

5. Kyle R. F., Gustilo R. B. And Premer R. F. Analysis of six hundred and twenty-two intertrochantenc hip fractures. J. Bone joint(Am). 1979;61: 216-21. 
6. Bhandari M, Devereaux PJ, Swiontkowski MF, Tornetta P, Obremskey W, Koval KJ, et al. Internal fixation compared with arthroplasty for displaced fractures of the femoral neck. A metaanalysis. J Bone Joint Surg Am. 2003 Sep;85$\mathrm{A}(9): 1673-81$.

7. Li, J., et al., [Application of dynamic hip screw with modified reamer in intertrochanteric fracture in the elderly]. Zhongguo Gu Shang, 2011. 24(5): p. 362-5.

8. Kempf, Grosse A,Taglang G, Favreul E. Gamma nail in closed trochanteric fracture.OrthopTraumatol Surg Res 2014 Feb;100(1):75-83.

9. E. Strauss, J. Frank, J. Lee, et al. Helical blade versus sliding hip screw for treatment of unstable trochanteric fractures: a biomechanical evaluationInjury. 2006;37 B(8) : 15-22

10. MoRRIs, H. D. : Trochanteric Fractures. Southern Medical Journal. 1998 Sep; 34, 571.
11. Bhandari M, Devereaux PJ, Tornetta PI, Swiontkowski MF,Berry DJ, Haidukewych G, et al. Operative management of displaced femoral neck fractures in elderly patients. Aninternational survey. Journal of Bone and Joint Surgery -American Volume2005;87(9):2122-30.

12. Broos PLO, Fourneau I. Intertrochanteric fractures: internal fixation or prosthetic replacement. Acta Orthopaedica Belgica 2000; 66(1):34-40.

13. Injury, Int. J. Care Injured. 2004. 35, 142-151

14. Kamble KT, Murthy BS, Pal V, Ráo KS. External fixation in unstable intertrochanteric fractures of the femur.1996. 27: 139-142

15. Rashid S, Dar G, Kangoo KA, Halwai MA. External fixation in the management of intertrochanteric fractures in elderly high risk patients.2008. IJO 8: 2.

To cite this article: Ayman M. Abbas, Galal El Din H. Kazem, Abd El Salam Abd El Alem Ahmed, Saad A. Shoulah. Different Methods of Treatment of Trochanteric Fractures in Elderly. BMFJ 2021; 38 (Orthopedic surgery):1-10. DOI: 10.21608/bmfj.2021.16787.1052 